\title{
Floral resource availability from groundcover promotes bee abundance in coffee agroecosystems
}

\author{
Kaleigh Fisher (D) ${ }^{1,4}$ David J. Gonthier, ${ }^{2}$ Katherine K. Ennis, ${ }^{3}$ and Ivette Perfecto ${ }^{1}$ \\ ${ }^{1}$ School of Natural Resources and Environment, University of Michigan, 3541 Dana Building, \\ 440 Church Street, Ann Arbor, Michigan 48109 USA \\ ${ }^{2}$ Department of Environmental Science, Policy and Management, University of California-Berkley, \\ 130 Mulford Hall, Berkeley, California 94720-3114 USA \\ ${ }^{3}$ Environmental Studies Department, University of California-Santa Cruz, Santa Cruz, California 95064 USA
}

\begin{abstract}
Patterns of bee abundance and diversity across different spatial scales have received thorough research consideration. However, the impact of short- and long-term temporal resource availability on biodiversity has been less explored. This is highly relevant in tropical agricultural systems for pollinators, as many foraging periods of pollinators extend beyond flowering of any single crop species. In this study, we sought to understand how bee communities in tropical agroecosystems changed between seasons, and if short- and long-term floral resource availability influenced their diversity and abundance. We used a threshold analysis approach in order to explore this relationship at two time scales. This study took place in a region dominated by coffee agroecosystems in Southern Mexico. This was an ideal system because the landscape offers a range of coffee management regimes that maintain heterogeneity in floral resource availability spatially and temporally. We found that the bee community varies significantly between seasons. There were higher abundances of native social, solitary and managed honey bees during the dry season when coffee flowers. Additionally, we found that floral resources from groundcover, but not trees, were associated with bee abundance. Further, the temporal scale of the availability of these resources is important, whereby short-term floral resource availability appears particularly important in maintaining high bee abundance at sites with lower seasonal complementarity. We argue that in addition to spatial resource heterogeneity, temporal resource heterogeneity is critical in explaining bee community patterns, and should thus be considered to promote pollinator conservation.
\end{abstract}

Key words: agroecosystem; bee community; biodiversity; coffee; conservation; seasonal complementarity; temporal resource availability.

\section{INTRODUCTION}

Land-use change, which includes habitat modification, fragmentation, and degradation, is a major contributor to changes in resource availability and thus bee population declines (Winfree et al. 2011, Potts et al. 2016). According to the Food and Agricultural Organization (FAO), agriculture is one of the strongest drivers of land use change, with over $40 \%$ of Earth's terrestrial surface dominated by agriculture (Foley 2006). The highest rates of agricultural intensification have been found in the tropics (FAO), which subsequently decreases the spatial and temporal availability of foraging resources for bees in tropical regions (Peters et al. 2013, Peters et al., 2016). Still, agricultural landscapes are not inherently unsuitable for biodiversity (Perfecto et al. 1996), and can in fact positively impact biodiversity (IPBES), particularly in the tropics (Gonthier et al.

Manuscript received 28 November 2016; revised 22 March 2017; accepted 12 April 2017. Corresponding Editor: Alison K. Brody.

${ }^{4}$ Present address: Department of Entomology, University of California-Riverside, 900 University Avenue, Riverside, California 92521 USA. E-mail: kalefish52@gmail.com
2014). Whether agricultural landscapes foster biodiversity, particularly bee populations, appears highly dependent on the level of management (Jha and Vandermeer 2010, Winfree et al. 2011, Mandelik et al. 2012), as it influences resource availability across spatial (Kremen et al. 2007, Williams et al. 2010, Kennedy et al. 2013, Ferreira et al. 2015) and temporal scales (Mandelik et al. 2012, Morellato et al., 2016, Leong et al., 2016, Geslin et al., 2016).

Coffee agricultural systems have become model systems to explore how agricultural intensification influences biodiversity and ecological interactions (Perfecto et al. 2014); coffee is managed across a large gradient of intensification, from farms that structurally resemble forests, with coffee grown underneath a diversity of shade trees, to sun coffee farms, without any non-crop vegetation. The ability of a coffee agroecosystem to support bee populations depends on its ability to maintain necessary foraging and nesting resource requirements (Michener 1969). In coffee farms in Indonesia, (Klein et al. 2003a,b) found that farms with greater resource heterogeneity supported a greater diversity of pollinators. While resource availability across multiple spatial scales has been shown to influence bee abundance and 
diversity in tropical landscapes (Tylianakis et al. 2008, Basu et al. 2016), the impact of temporal resource heterogeneity (differences in availability of resources throughout time) on biodiversity has been less explored (Mandelik et al. 2012, Morellato et al. 2016, Geslin et al. 2016, Leong et al. 2016). Bees use resources from an array of plant species to satisfy different nutrition requirements throughout their foraging season, which typically extends beyond the flowering event of a single plant species (Baker 1963, Olesen 2008). Thus, sites that have floral resources available throughout the year may satisfy bee foraging requirements, whether by a single flowering species that is always in flower or through multiple plants that flower at different times (seasonal complementarity; Bluthgen and Klein 2011, Mandelik et al. 2012). Understanding seasonal resource patterns is particularly important in the tropics because tropical bees forage all year long (Roubik 1989). Further, because the tropics maintain less seasonal extremes than temperate zones, seasonal variation imposed by climate change may have more dramatic effects on flowering phenologies (Buckley and Huey 2016, Morellato 2016).

In this study, we sought to understand how seasonal complementarity of non-crop floral resources influences bee diversity and abundance in a coffee agroecosystem with two well-defined seasons. Coffee farms offer a valuable opportunity to explore these patterns because they are managed under a variety of shade tree regimes (Moguel and Toledo 1999). This leads to a natural gradient of temporal floral resource availability, from farms that provide no floral resources outside of the coffee flowering, to farms where non-crop floral resources are staggered. We addressed the following questions: (1) How does the community composition of bees change across seasons in a tropical coffee agroecosystem? (2) Is pollinator diversity and abundance better explained by available floral resources or seasonal complementarity in floral resources (i.e., short vs. long temporal scales)?

For question 1, we predicted that the community composition of bees would change between the two different seasons, as bee communities have been found to vary in composition due to temporal drivers (Aranda and Graciolli 2015, Rollin et al. 2015, Samnegård et al. 2015). There are fewer floral resources from trees in the rainy season, so we expected native social bees to be favored in the dry season, when there are more floral resources to sustain their nests. We predicted native solitary bees to be favored in the rainy season, as they are generally smaller bodied, which has been found to be favored in the rainy season in previous studies (Samnegård et al. 2015). We did not expect the managed honey bee (Apis mellifera scutellata) to change during the different seasons, as they are given supplemental resources consistently throughout the year and are thus buffered from resource fluctuations (E. Jiminez-Soto, personal communication).

Building on previous spatial studies to address question two, where local and landscape-level patterns interact to explain bee abundance (Tscharntke et al. 2005), we predicted that short and long temporal scales would also interact to explain bee abundance and richness, where the longer temporal scale controls the shorter scale. We predicted that more continuous levels of sitelevel floral resources during the sampling event from trees would explain high bee abundance and richness (Jha and Vandermeer 2010). Similarly, we predicted that habitats with more continuous levels of local-floral resources from trees throughout different seasons (seasonal complementarity) would also generate high bee abundance and richness (Kovacs-Hostyanszki et al. 2013). More specifically, we predicted that sites with more even resources across longer temporal scales would limit the importance of floral resource availability at shorter scales. Further, we predicted that the temporal interaction of floral resource availability would vary depending on the sociality group (i.e. native solitary, native social, or managed social), due to differences in foraging strategies (Rollin et al. 2015).

\section{Methods}

\section{Study area}

This study was conducted from June 2014 to April 2015 in the Soconusco region of Chiapas $\left(15^{\circ} 10^{\prime} 15^{\prime \prime} \mathrm{N}\right.$; $92^{\circ} 20^{\prime} 33.192^{\prime \prime} \mathrm{W}$ ), a coffee growing region in Mexico. We selected sites across three farms that ranged in management intensification (Moguel and Toledo 1999, Philpott et al. 2008). The rainy season takes place from May to November and the dry season takes place from December to April. Twenty-five $20 \times 20 \mathrm{~m}$ sites were established based on the estimated temporal composition of floral availability provided by plant species within each site, with 13 sites in a commercial polyculture farm and 12 sites distributed between two shaded monoculture farms. ${ }^{5}$ All sites were at least $100 \mathrm{~m}$ apart. Sites were evenly distributed between the commercial polyculture farm and between the two functionally similar shade monoculture farms. However, we ultimately used only 22 sites due to significant tree removal at three sites half way through the execution of this project.

Sites were selected according to a gradient of temporal floral resource availability from shade trees, which had previously been found to be the most important resource strata for the bee community at these farms (Jha and Vandermeer 2010). Sites were selected if they conformed to one of the following categories: (1) tree species with continuous floral resources available throughout the year, or a combination of dry and rainy season flowering trees; (2) tree species with floral resources available only in the dry season; (3) floral resources available only in the rainy season; and (4) trees without floral resources

\footnotetext{
${ }^{5}$ Seasonal floral resource availability from trees was determined from previous personal observations at this field site, as well as from reported phenologies of specific species. http:// www.tropicos.org
} 
for animals (Appendix S1: Table S1). The combination of the four site types during one sampling event represented a gradient of short-term resource availability. The four repeated sampling events across each site type produced a gradient of long-term resource availability. All sites had coffee, which flowers in February during the dry season (Philpott et al. 2006) and flowering groundcover. Floral resources and bee abundance/richness were measured twice at each site during the rainy season, June 2014 and July $2014(n=35)$ and twice during the dry season, January 2015 and February $2015(n=44)$. For the July sampling event, only sites in one farm were collected $(n=13$; Appendix S1: Table S5) due to sampling limitations. We performed vegetation and pollinator surveys simultaneously during each sampling event.

\section{Vegetation survey}

Floral resources from trees, herbaceous groundcover (hereafter GC), and coffee were all measured. The availability of floral resources from trees was estimated according to canopy cover, proportion of trees in flowers, flowering tree abundance and flowering tree richness. The availability of floral resources from GC was estimated according to richness of GC in flower (based on morpho-species) and percentage of GC in flower. Canopy cover was measured at five points throughout the site using a handheld spherical densitometer. The proportion of trees in flower was calculated by counting the number of trees in flower over the total number of trees in the site. GC was measured by randomly placing four $0.5 \times 0.5 \mathrm{~m}$ quadrats within each site and measuring the percent $\mathrm{GC}$ in each quadrat and the percentage of flowering herbs within each quadrat. Percent GC in flower was calculated by taking the proportion of flowering herbs to the total GC. When coffee was in flower (February), the percentage of coffee in flower was determined by selecting three coffee bushes and counting flowers and buds.

\section{Pollinator survey}

To quantify pollinator abundance and diversity at each site during one sampling event, pollinators were collected using pan traps and sweep nets. All bees collected during one sampling event were combined into a single sitesampling event value. Thirty $148-\mathrm{mL}$ (Gordon's Food Supply, Wyoming, MI, USA) plastic bowls (10 blue, 10 white, 10 yellow) were placed across each site in the shape of an $\mathrm{x}$ through the center of each site (LeBuhn et al. 2003, Jha and Vandermeer 2010). Pan traps were set out before 09:00 and collected right before it began to rain in the rainy season (around 13:00), and 14:00 in the dry season. All insects caught in the pan traps were preserved in alcohol in the field. Specimens were later separated and identified to species, or morpho-species, in the lab with field guides (Michener et al. 1994), reference collections from El Colegio Frontera Sur, and comparisons from previous studies (Novelo et al., 2007, Jha and Vandermeer 2010). We observed bee foraging at each site between the hours of 09:00 and 11:00, optimum foraging hours for bees in this region (Jha and Vandermeer 2010). We performed observations for $10 \mathrm{~min}$ at each site on the same day pan traps were laid out. Bees found foraging on GC or low trees were either identified on site, or collected for later identification. During coffee flowering, coffee bushes were also observed for a period of $10 \mathrm{~min}$.

\section{Statistical methods}

We performed all the analyses considering representative month-pairs for each season: June and July (rainy season), January and February (dry season). We analyzed the differences in community composition between the month-pairs using a nonmetric multidimensional scaling analysis (NMDS). We then conducted an analysis of similarity (ANOSIM) using a Bray-Curtis similarity index as the similarity measure in PAST (Hammer et al. 2001). The ANOSIM compares the mean distance within a group to the mean distance between groups; this statistically determines separation in species composition between the two different seasons (Jimenez-Soto and Philpott 2015).

To see what was explaining the differences in community composition between the sampling events, we used generalized linear mixed models (GLMM) with Poisson error distributions (Bolker et al. 2009) using the glmer package lme4. We ran models with month (sampling event) as a fixed effect, and site, as a factor of season, and farm as random effects to account for any differences from site- and farm-level variation. We ran all models for the following response variables: bee abundance, native social bee abundance, native solitary bee abundance, and managed bee abundance. We then performed post-hoc analyses using the glht function in the mulcomp package in $\mathrm{R}$. This function performs pairwise comparisons of categorical fixed effects. Finally, we used the car package to perform Wald Type III tests to determine overall model significance.

To compare how short and long term temporal resource availability influence bee abundance and richness, as well as to see if they interact, we created two metrics to quantify floral resource availability at the two temporal scales, which we could statistically compare across sites as well as between sampling events. The first metric combined individual floral resource variables across the four sampling events to quantify long-term resource availability. This metric was then divided into metric $1 \mathrm{a}$, which represents long-term resource availability from trees (abundance, richness, and percentage of trees in flower), and metric $1 \mathrm{~b}$, which represents long-term resource availability from GC (richness and percentage of flowering GC). The second metric considered short-term floral resources from trees at each sampling event (metric 2a) and short-term floral resources from GC at each sampling event (metric 2b) (Appendix S1: Table S2). 
These metrics were determined using a threshold analysis approach, which has previously been employed in other studies to integrate effects of multiple variables into a single metric (Byrnes et al. 2014, Lefcheck et al. 2015). This approach assigns a value only to variables that exceed a threshold percentage for resource level. The threshold represents a percentage of the maximum value of the variable across sites sampled. We used this approach to account for variation in amount of resources available, rather than average resource availability or variability in resources (CV) across time.

In order to combine multiple variables into one metric, each individual variable (i.e., tree variables or $\mathrm{GC}$ variables) that is put into the metric is considered as a response variable. Theoretically considering one variable across four sampling events, if the response variable exceeds the selected threshold percentage, that variable receives a value of 1 for that sampling event and if it is below 1 then it receives a value of 0 , with a maximum value of 4 (the variable exceeding the threshold percentage during four sampling events) and minimum value of 0 (the variable never exceeding the threshold percentage). To select the best threshold percentage, all possible threshold percentages from 5\% to $95 \%$ were run to generate values for the relevant variable and compared with bee richness. The threshold percentage was selected based on which percentage's value was best correlated with bee richness (Appendix S1: Figs. S1, S2).

Each variable that was included in metric $1 \mathrm{a}$ or $1 \mathrm{~b}$ was given a threshold value. These individual values were then summed for the temporal floral resources from trees (metric 1a) metric or for temporal floral resources from GC (metric 1b). Metric 1a had a final range from 0 to 11 , and Metric $1 \mathrm{~b}$ had a final range from 0 to 6 . The 0-11 range for metric 1a is produced from two variables (tree abundance and tree richness) measured during four sampling events, and one variable (percentage of trees in flower) measured during only three sampling events, due to limited sampling in July. GC species richness and percentage of GC in flower were used to calculate metric $1 \mathrm{~b}$ and these variables were only quantified during three sampling events: June, January, and February.

To quantify short-term resources from trees, (metric 2a), the three variables that characterize floral resources from trees were quantified together to select the best threshold percentage (Appendix S1: Fig. S1). Values were assigned to each site for every time period based on how many of the three variables exceeded the threshold. All possible threshold percentages, from $5 \%$ to $95 \%$, were run to generate values for the metric, which were then compared to bee richness in order to select the most predictive percentage (Appendix S1: Fig. S2). The percentage used to calculate the metric was selected based on which percentage's value was best correlated with bee richness, or had the highest slope (Appendix S1: Fig. S2). Metric 2a has a range from 0 to 3 . This was then repeated for metric $2 b$ (short-term resources from GC), which included the two variables that quantified floral resources from GC (Appendix S1: Fig. S1). Metric $2 \mathrm{~b}$ has a range from 0 to 2 .

We tested all of the final metric values for collinearities by calculating correlation coefficients using linear regressions (Appendix S1: Table S3). To understand the effect of short- and long-term floral resource availability on the response variables bee abundance, bee richness, native social bee abundance, native solitary bee abundance, and managed social bee abundance, we used generalized linear mixed effect models (GLMM) using the glmer package lme4. All models were run with a Poisson error distribution and logit link function (Bolker et al. 2009). We constructed five candidate models with the following fixed effects: (1) interaction between short and long term resource availability from trees (ITR), interaction between short and long term resource availability from GC (IGCR) + coffee + season; (2) ITR + coffee + season; (3) IGCR + coffee + season; (4) ITR + IGCR + coffee; (5) ITR + IGCR + season. For each model, site, as a factor of season, and farm were included as random effects to account for any differences from site and farm level variation. We then used the package AICcmodavg to conduct maximum likelihood comparisons to select the best model according to Akaike's information criterion (AIC). To determine term significance for the bestfit models, we compared nested models, starting with the best-fit model as the global model, and performed likelihood ratio tests with the package lmtest. To see if predictor variables correlated with response variables, we ran Spearman rank correlations, to account for non-parametric data. Finally, we ran percent canopy cover as a predictor variable, as canopy cover has previously been found to impact bee community composition.

Because some of our sites were only $100 \mathrm{~m}$ apart, the degree of spatial autocorrelation in the residuals of the best-fit models was tested using Moran's $I$ test for spatial autocorrelation with the ape package. We did not find spatial autocorrelation at any of our sites (Appendix S1: Table S4) and thus considered our sites to be spatially independent. All statistical analyses were performed with the software R-Studio v. 0.98 .1103 for Macintosh and PAST v. 3.04.

\section{RESULTS}

We identified 796 bees of 31 species in three families. Most bees collected were in the family Apidae $(62.9 \%$ of individuals collected) and Halictidae (37\% of individuals collected). The most abundant species was Apis mellifera scutellata, the Africanized honey bee, which are kept in managed hives on the farm. The second most abundant species was Ceratina ignara, a solitary Apidae species. Across sites and months, bee abundance ranged from 0 to 35 within a sampling period, with an average of 8.9 bees per site. Bee richness ranged from 0 to 12 , with an average of 3.8 species per site. A total of 312 bees were caught during the rainy season and 484 bees were caught during the dry season. Flowering vegetation varied 
between sites and seasons. Flowering tree richness ranged from 0 to 4 species in flower at a given sampling event at one site. Flowering tree abundance ranged from 0 to 10 trees. The percentage of trees in flower ranged from 0 to $63 \%$. The percentage of $\mathrm{GC}$ in flower ranged from 0 to $35 \%$ and the richness of GC in flower ranged from 0 to 7 species (Appendix S1: Table S5).

\section{Changes in the bee community based on season}

Bee community composition differed between the two seasons, and differed between each sampling event ( $R=0.2406$ ). The NMDS comparing the four months showed an apparent difference (stress $=0.4606$; Fig. 1) visually. We confirmed this difference statistically with an analysis of similarity (ANOSIM) and found significant differences in the bee community between June and July, both in the rainy season $(P=0.0018)$, between January and February, both in the dry season $(P=0.0066)$, and between the dry and rainy season (Appendix S1: Table S6).

\section{Temporal changes in bee abundance and richness}

Bee abundance across all sites was significantly higher in February, when the coffee was flowering, than any other sampling event $\left(\chi^{2}=43.4 ; \mathrm{df}=3 ; \quad P<0.001\right.$, Fig. 2). Coffee flowering was positively correlated with bee abundance and bee richness, while canopy cover negatively correlated with bee richness (Table 1). Short- and long-term temporal availability of floral resources from
GC interacted to influence bee abundance $\left(\chi^{2}=43.4\right.$, $P<0.001$; Appendix S1: Table S7) at individual sites. At sites with low seasonal complementarity in floral resources from $\mathrm{GC}$, high short-term floral resources from GC were positively associated with bee abundance. However, at sites with floral GC resources more consistently available between the two seasons, short-term floral resources did not significantly correlate with bee abundance (Fig. 3). Thus, high short-term floral resource availability from GC was important in explaining bee abundance at sites that did not maintain consistent floral resources throughout the year. Floral resources from trees were not included in the best model for bee abundance, but long-term tree floral resources were for bee richness (Table 2). However, long-term floral resources from trees did not significantly correlate with bee richness. High seasonal complementarity in floral resources from GC was positively correlated with bee richness, but short-term floral resources from GC did not (Table 1).

\section{Temporal changes between sociality groups}

Native bee abundance-Abundance of native social bees remained constant between the four sampling events, except for in January of the dry season, where it was significantly lower $\left(\chi^{2}=43.4\right.$, df $=3, P<0.001$; Fig. 2$)$. Native social bee abundance was positively correlated with coffee flowering and negatively correlated with canopy cover (Table 1). Short- and long-term temporal resource availability from $\mathrm{GC}$ interacted to influence native social bee abundance $\left(\chi^{2}=12.9 ; \quad P<0.001\right.$;

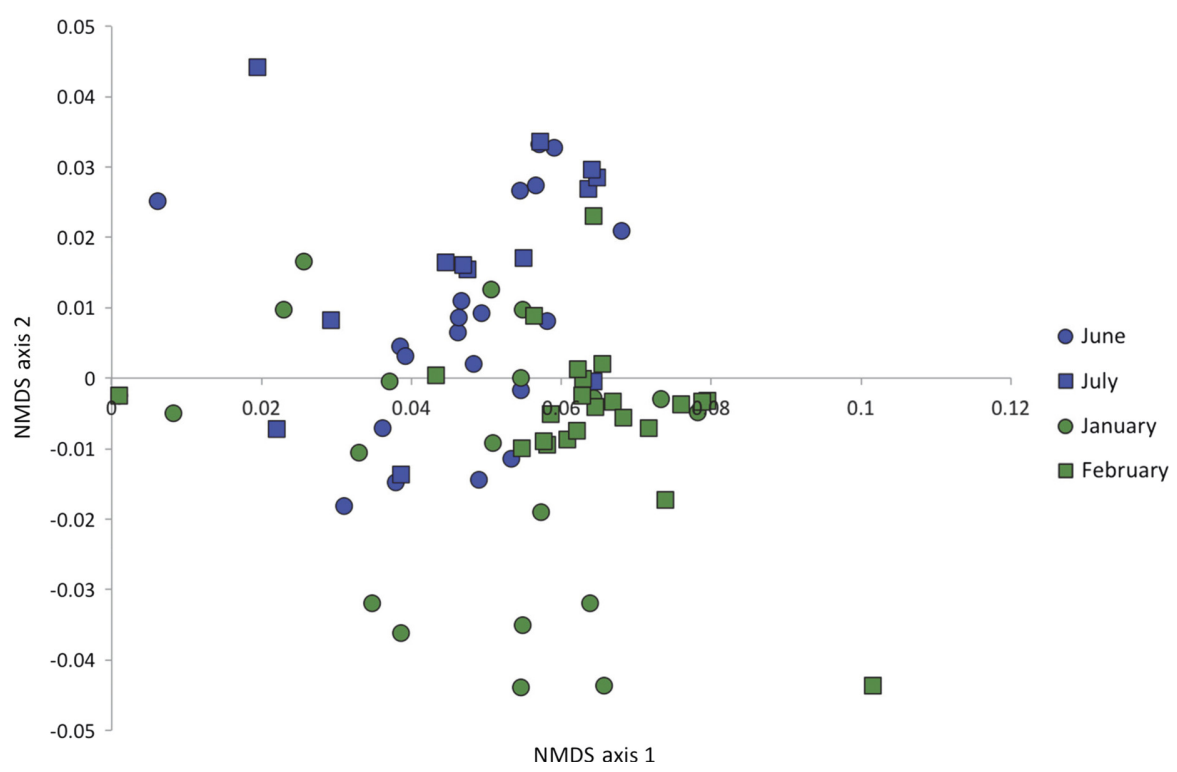

FIG. 1. Results of nonmetric multidimensional scaling (NMDS) analysis performed on community composition of bees between each sampling event. There is an apparent difference in the bee community between each sampling event (stress $=0.4606)$. Blue squares and circle represent the months sampled during the rainy season; green squares and circle represent the months sampled during the dry season. [Color figure can be viewed at wileyonlinelibrary.com] 

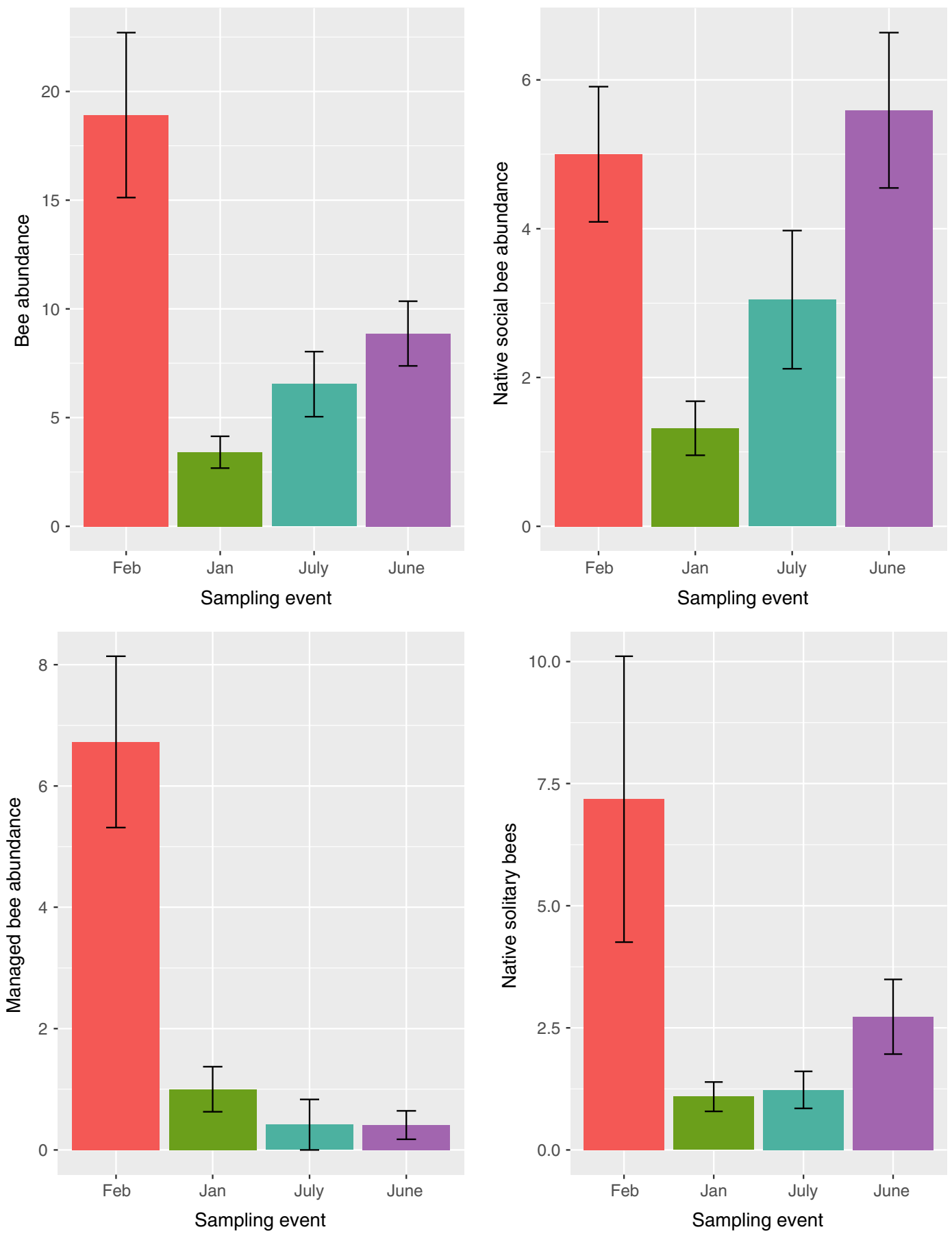

FIG. 2. Bar graphs showing average (A) bee abundance, (B) native social bee abundance, (C) native solitary bee abundance, and (D) managed bee abundance across all sites for each sampling event. (A) There are significantly more bees in February than the three other sampling months. (B) There are significantly fewer native social bees in January than the other sampling events. (C) There are significantly more native solitary bees in February than the three other sampling months. (D) There are significantly more managed bees in February than the other three sampling months. Error bars show one standard error above and below the mean. [Color figure can be viewed at wileyonlinelibrary.com]

Appendix S1: Table S7). At sites with less seasonal complementary in floral resources from GC, high short-term resource availability from GC positively impacted native bee abundance. At sites with more consistent floral resources from GC between the two seasons, high, short-term resource availability did not significantly impact native social bee abundance (Fig. 3). This suggests that short-term floral resource pulses are 
TABLE 1. Results of Spearman rank correlations.

\begin{tabular}{|c|c|c|c|}
\hline Predictor variable & $S$ & $\rho$ & $P$ \\
\hline \multicolumn{4}{|l|}{ Bee abundance } \\
\hline Coffee flowering & 42292.71 & 0.48 & $<0.001$ \\
\hline Canopy cover & 98788,46 & -2.02 & 0.07 \\
\hline \multicolumn{4}{|l|}{ Bee richness } \\
\hline Trees total & 72769.87 & 0.1142 & 0.3159 \\
\hline GC total & 51830.34 & 0.369 & $<0.001$ \\
\hline Coffee flowering & 48243.82 & 0.4128 & $<0.001$ \\
\hline Canopy cover & 104805.2 & -0.275 & 0.013 \\
\hline \multicolumn{4}{|l|}{$\begin{array}{l}\text { Native social bee } \\
\text { abundance }\end{array}$} \\
\hline Coffee flowering & 86541.15 & 0.23 & 0.02 \\
\hline Canopy cover & 103412.6 & -0.258 & 0.02 \\
\hline \multicolumn{4}{|l|}{$\begin{array}{l}\text { Native solitary bee } \\
\text { abundance }\end{array}$} \\
\hline Trees total & 66040 & 0.196 & 0.08 \\
\hline GC total & 46736 & 0.43115 & $<0.001$ \\
\hline Coffee & 58816.85 & 0.284 & 0.01 \\
\hline Canopy cover & 103410.4 & -0.258 & 0.02 \\
\hline \multicolumn{4}{|c|}{ Managed bee abundance } \\
\hline Present trees & 53627 & 0.32 & $<0.001$ \\
\hline Canopy cover & 70395 & 0.1098 & 0.3386 \\
\hline GC present & 71046 & 0.101 & 0.3762 \\
\hline Coffee & 28496 & 0.63 & $<0.001$ \\
\hline
\end{tabular}

Notes: Significant predictor variables are shown in boldface type. GC, herbaceous ground cover. All $\mathrm{df}=1$.

important in explaining native bee abundance patterns at sites that do not have consistent floral resources seasonally, similar to what was found for total bee abundance.

Solitary bee abundance - Native solitary bee abundance remained constant throughout the four sampling events, except during February, where it significantly increased $\left(\chi^{2}=79.8\right.$, df $=3, P<0.001$; Fig. 2). Native solitary bee abundance was found to significantly correlate with coffee flowering (Table 1), which occurs in February. Long-term floral resources from trees were kept in the best model predicting solitary bee abundance (Table 2), and were found to positively correlate with solitary bee abundance (Table 1). Canopy cover was also negatively correlated with solitary bee abundance (Table 1).

Managed honey bee abundance - The abundance of managed honey bee was significantly higher during the period in which coffee was flowering $\left(\chi^{2}=84.2\right.$, df $=3$, $P<0.001$; Fig. 1). Short-term resources from trees and coffee flowering were positively correlated with honey bee abundance (Table 1).

\section{Discussion}

Seasonal resource complementarity is important to support the bee community in which complementarity in floral resources through time functions to satisfy foraging requirements of bees throughout their foraging season. In coffee agroecosystems, coffee is grown under shade trees and in the presence of flowering GC. These agroecosystems have the potential to support bee resource requirements seasonally, depending on the intensity of their management. We found more bees to be active during the dry season, which can be explained by the greater abundance of flowering plants. Still, bees were found foraging in the rainy season, as well as in the dry season outside of major flowering events. The bee community differed between the two seasons, as well as between sampling events. The presence of bee foraging during the two seasons, as well as differences in the bee community, exemplifies the importance of understanding seasonal resource complementarity. We found that short-term and long-term temporal resource availability from $\mathrm{GC}$, but not from trees, interact to explain bee abundance. In fact, we only found floral resources from trees to be important in explaining managed honey bee abundance, but not native bee abundance or richness. This was surprising, as these resources have previously been found to be critical for native bees (Cairns et al. 2005, Jha and Vandermeer 2010).

Previous studies have considered the impact of seasonal complementarity on bee abundance and richness from theoretical perspectives (Bluthgen and Klein 2011), complementary habitat use between seasons (Mandelik et al. 2012), effects of steady state floral resource availability from a single non-crop plant (Peters et al. 2013) and seasonal shifts in bee abundance and richness (Leong et al. 2016). These studies have been foundational in understanding how seasonal flowering phenologies impact bee abundance and diversity, which has been arguably understudied. However, no studies to date have explored how seasonal flowering phenologies interact within the same site across different time scales.

\section{Changes in the bee community based on season}

We found that bee community composition differs between the two seasons, and the four sampling events. Each sampling event had different combinations of floral resources available. The floral resources available are determined by flowering phenologies of trees and coffee. However, the availability of GC on the farm is more reflective of management decisions, than intrinsic phenology. Under normal management, GC is completely removed several times per year, which disrupts available floral resources for bees from this source. However, GC grows back and flowers within a few weeks (K. Fisher, personal observation). We speculate that the flowering species, and strata (trees, GC, etc.), during a sampling event impact how and where bees forage for resources. Previous empirical studies have reported how bee foraging behavior shifts with seasonal variation in resource availability across tropical landscapes (Aranda and Graciolli 2015, Aleixo et al. 2016, Kaluza et al. 2016). Native bees foraging on high quality resources have been 

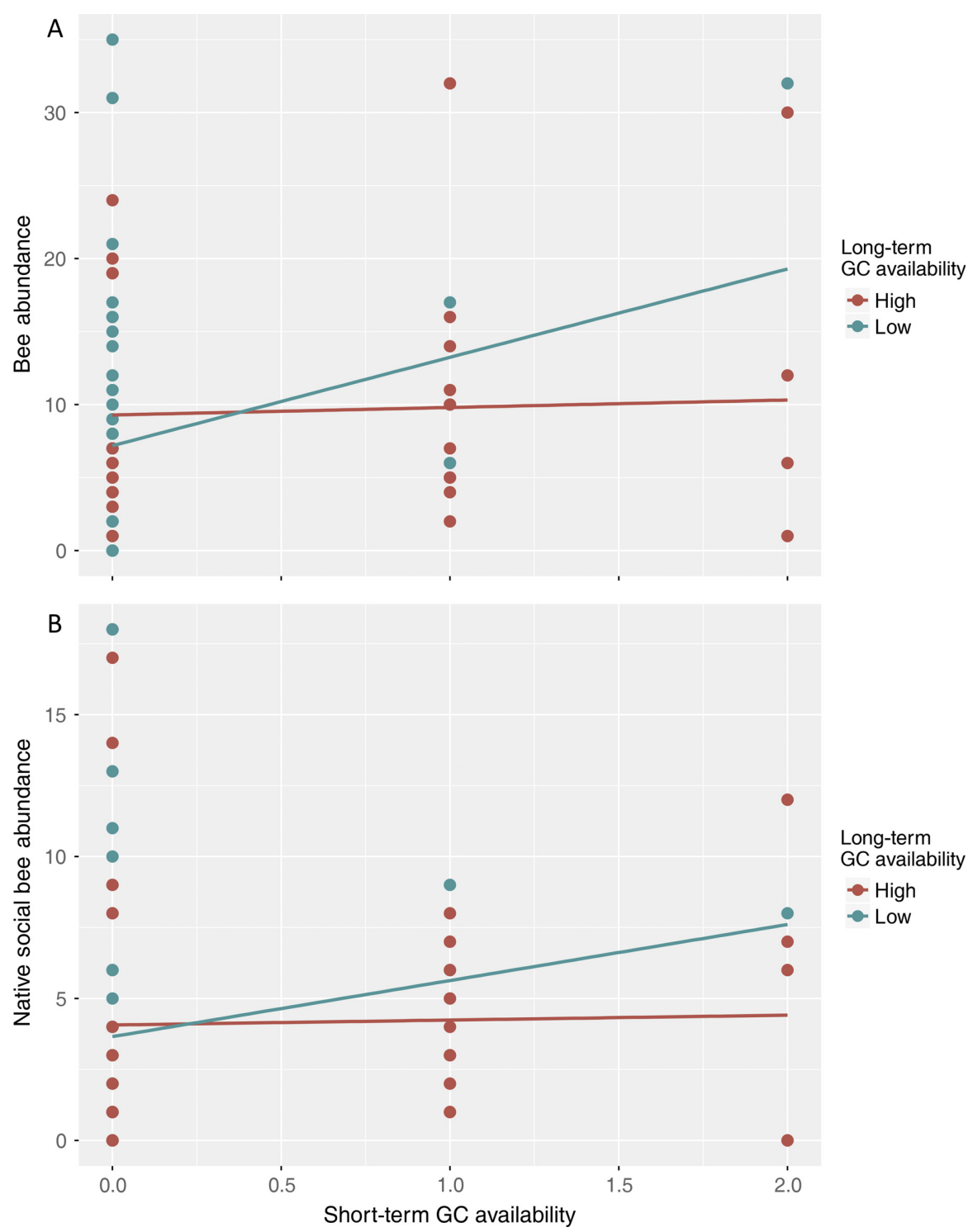

FIG. 3. The effect of the interaction between floral resources from herbaceous groundcover (GC) on (A) total bee abundance and (B) native social bee abundance. The $x$-axis represents short-term resource availability from GC. When there is lower complementarity in long-term resource availability from GC, short-term resource availability from GC is more important in explaining bee abundance. [Color figure can be viewed at wileyonlinelibrary.com]

found to be displaced in the presence of managed honey bees (Roubik and Wolda 2001). If there are other resources available concurrently with the displacement, they will persist by foraging on the other resources, possibly of lower quality, which may explain why managed honey bee responded to short-term resource availability from trees but not other bees. Similarly, if one group is displaced by another on coffee, they can still be found foraging on flowering trees or herbaceous GC. Each sampling event has a different combination of floral resource strata (i.e., GC, trees, coffee), with varying abundances and richness, which may explain why we see strong differences in community composition of bees during the different seasons.

\section{Temporal changes in bee abundance and richness}

Bee abundance did not respond to floral resources from trees, which was unexpected as previous studies have shown the importance of trees in predicting bee abundance and richness (Klein et al. 2003a, $b$, Jha and Vandermeer 2010) in the tropics. The variation we found in floral resources from trees across our sites was much smaller than the previous study in this system (Jha and Vandermeer 2010), which may have reduced its signal. Further, between the years of these studies, one of the farms we sampled significantly reduced the number of shade trees (I. Perfecto, personal communication). Additionally, native bees may respond to a larger spatial scale 
TABLE 2. Statistical results of generalized linear mixed effect models (GLMMs) analyzing the effect of short-term and long-term temporal resource availability from trees and their interaction, short-term and long-term temporal resource availability from GC and their interaction, presence of coffee flowering, and season on bee abundance, richness, and abundance of bee sociality groups.

\begin{tabular}{|c|c|c|c|c|c|c|c|c|c|}
\hline Response variable & Best model & SGC & LGC & IGCR & ST & LT & ITR & $\mathrm{CF}$ & Season \\
\hline Bee abundance & $\mathrm{SGC} \times \mathrm{LGC}+\mathrm{CF}+$ Season & $<0.01$ & $<0.001$ & $<0.01$ & NA & NA & NA & $<0.001$ & $<0.001$ \\
\hline Bee richness & $\mathrm{LT}+\mathrm{LGC}+\mathrm{CF}+$ Season & NA & $<0.001$ & NA & NA & 0.47 & NA & $<0.001$ & $<0.001$ \\
\hline Native social bee abundance & $\mathrm{SGC} \times \mathrm{LGC}+\mathrm{CF}+$ Season & $<0.001$ & $<0.01$ & $<0.001$ & NA & NA & NA & $<0.001$ & $<0.001$ \\
\hline Native solitary bee abundance & $\mathrm{LT}+\mathrm{LGC}+\mathrm{CF}+$ Season & NA & $<0.001$ & NA & NA & 0.08 & NA & $<0.001$ & $<0.001$ \\
\hline Managed bee abundance & $\mathrm{SGC}+\mathrm{ST}+\mathrm{CF}+$ Season & 0.29 & NA & NA & 0.72 & NA & NA & 0.059 & $<0.001$ \\
\hline
\end{tabular}

Notes: SGC, short-term GC availability; LGC, long-term GC availability; IGCR, groundcover resource interaction; ST, shortterm tree resource availability; LT, long-term tree resource availability; ITR, tree resource interaction; CF, coffee flowering. NA indicates that variable was not included in the best model. Numbers show $P$ values for predictor variables as determined by likelihood ratio tests.

than we used for this study (Jha and Vandermeer 2010). Floral resources from GC however, were very important in explaining total bee abundance throughout the year. These resources interacted between the two time scales, where short-term resource availability was more impactful at sites with less consistent seasonal complementarity. Our results suggest that sites with higher seasonal complementarity may sustain bee foraging requirements, even at times where short-term resources are low. Previous studies have found that bees shift from agricultural habitats, when there are fewer floral resources available from crops, to more consistent resources in semi-natural habitats surrounding farms (Mandelik et al. 2012). Because we explored our question in a coffee system that had sites with floral resources from multiple species and strata, we were able to find patterns of complementarity within a single habitat rather than across habitats.

Bee richness was influenced by long-term availability of floral resources from GC, but not short-term availability. This may be because different bee species' dependence on GC varies throughout the year depending on species and strata-specific floral resource availability.

\section{Temporal changes between sociality groups}

Floral resource availability influenced bee groups differently as we expected, except for their positive response to coffee flowering. This is reasonable, as coffee is a mass flowering, high-quality resource that is abundant throughout the landscape when it flowers. Bees employ different recruitment strategies in response to mass flowering crops depending on sociality: managed honey bees forage with a concentration effect, whereas native solitary and social bees exhibit a dilution effect in their foraging response to increases in floral resources. Additionally, different groups have been shown to respond to resources at different spatial scales; native social and solitary bees respond to resources at smaller spatial scales than managed honey bees (Jha and Vandermeer 2009). This may explain why they responded to temporal availability of resources in different ways in our system.
The abundance of native social bees did not change significantly between sampling events, except for significantly decreasing in January, which had the lowest number and richness of trees in flower (Appendix S1: Table S1). Previous studies have found this group to respond the strongest to increases in floral resource availability from trees (Jha and Vandermeer 2010), which may explain why their abundances decreased during this sampling event. But neither short-term or longterm temporal floral resources from trees were found to correlate with native bee abundance. Like total bee abundance, native social bee abundance responded to an interaction between short-term and long-term temporal resource availability from GC.

Both foraging and nesting resources from trees have been found to be important for native social bees (Jha and Vandermeer 2010). Abundance may have been lower in January because they avoided floral resources occupied by other species (Johnson and Hubbel 1974, Nagamitsu and Inoue 1997) by shifting resource use (Roubik 1978, Roubik et al. 1986, Cairns et al. 2005). Native social bees have been found to respond negatively to greater distance to forest (Klein et al. 2003a,b, Ricketts 2004, Brosi and Briggs 2013). In a previous study at the farms we sampled in, distance to forest did not impact bee abundance. This was explained by the diversity of within-farm resources being sufficient in sustaining resource requirements (Jha and Vandermeer 2010). But since the significant shade tree removal in 2012, the forest fragments adjacent to the farms may now be relatively more valuable than they were during the previous study. The native social bees may have shifted to forest fragments during this time, which would explain their relatively low numbers on the farm.

Native solitary bees did not change in their abundance during the four sampling events, except increasing in February. Native solitary bees strongly correlated with presence of coffee and seasonal complementarity in floral resources from GC. This is similar to findings from previous studies, which have found solitary bees to respond to flowering GC (Klein et al. 2003b, Mandelik et al. 2012) and species richness of flowering herbs (Jha and 
Vandermeer 2010). A high percentage of canopy cover has also been found to be important for these bees because it provides access to nesting sites (Jha and Vandermeer 2010), however, canopy cover was actually negatively correlated with bee abundance. This may be because canopy cover decreases availability of herbaceous GC (Jha and Vandermeer 2010). While most solitary bees forage on coffee flowers (Klein et al. 2003b), they will switch to GC resources when social bees are foraging (Willmer and Stone 1989, Klein et al. 2002). This may explain why they have high abundances during the coffee flowering event, despite increases in other bee groups.

Managed honey bees were found in the highest proportions during the dry season when coffee was flowering (February). This is contrary to what we expected, as we predicted that their proportion would remain the same as they were given supplemental resources at the apiaries during our sampling events. Social bees have been found to positively correlate with blossom cover of coffee (Klein et al. 2003a,b). The Africanized honey bee exhibits a concentration effect in response to mass flowering, where they increase visitation with increases in floral resource abundance (Veddeler et al. 2006, Jha and Vandermeer 2009). Managed honey bees only correlated with coffee flowering (February) and short-term resources from trees. Coffee flowers are high quality and abundant resources for bees when they are available. As the managed honey bees have been found to be the best competitor in obtaining high quality floral resources (Roubik 1978, Roubik et al. 1986, Cairns et al. 2005) it is reasonable that they would significantly respond to coffee flowering. Still, floral resources from trees may also offer higher quality resources outside the coffee flowering event. As Africanized honey bees have been found to be better competitors, they may be displacing the other social groups from foraging on trees.

\section{CONCLusion}

Floral resource availability, which is determined by management decisions in agricultural landscapes, is a key driver of species abundance and richness (Tylianakis et al. 2008). It has been shown that changes in land use can lead to resource-mediated pollinator declines (Holzschuh et al. 2007, Kennedy et al. 2013). Previous studies have found that resource heterogeneity at the local and landscape spatial scale interact to explain diversity, where diversity is positively impacted by improvements in local resource availability in more simplified landscapes (Tscharntke et al., 2005). We used this as a model to explore how bees respond to different temporal scales. Similar to bee patterns across spatial scales, we found that short-term temporal resource availability was more important for bee abundance at sites that had less consistent long-term resource availability, a novel finding to our knowledge. In addition to spatial resource heterogeneity, temporal resource heterogeneity is also critical in explaining patterns of bee abundance and richness.
The Intergovernmental Science-Policy Platform on Biodiversity positively and Ecosystem Services recently evaluated knowledge of pollinators and pollination (2016) and concluded that agricultural systems have the potential to support pollinators. In conjunction with this report, Dicks et al. (2016) suggested the following policy objectives: policies should be implemented that support agroecological (ecological intensification) farming practices, which support ecological functions like pollination and pest control. As part of these complementary objectives, we suggest that seasonal, or temporal, availability of resources should be considered to understand patterns of bee abundance and diversity and to implement successful conservation strategies. Specifically, farms can support pollinators by maintaining complementarity in floral resources available from both crop and non-crop plants as part of diversification of their farms. Future studies should further investigate the physiological and ecological mechanisms driving these patterns. Particularly, they should consider how specific bee groups shift resource use depending on flowering patterns and abundances of different plant species, physiological requirements at different life history stages (nesting, nutritive, immune, etc.) and competition with other insects.

\section{AcKNOWLedgments}

We would like to thank Oscar Gustavo Lopez Bautista, Braulio E. Chilel, and Aldo de la Mora Rodriguez for assistance in the field during this project. We also thank the Peters family and the Finca Irlanda Consortium for allowing us to conduct research on their farm. We thank Theresa Ong, Jonathon Morris, and Esteli Jiminez-Soto for guidance on statistical analyses. Finally, we wish to thank Mark D. Hunter, Aldo de la Mora Rodriguez, and two anonymous reviewers for thoughtful suggestions that greatly improved this manuscript.

\section{Literature Cited}

Aleixo, K. P. A., C. M. Enezes, V. Lúcia, I. M. F. Onseca, C. Inês, and S. Ilva. 2016. Seasonal availability of floral resources and ambient temperature shape stingless bee foraging behavior (Scaptotrigona aff. depilis). Apidologie. https:// doi.org/10.1007/s13592-016-0456-4

Aranda, R., and G. Graciolli. 2015. Spatial-temporal distribution of the Hymenoptera in the Brazilian Savanna and the effects of habitat heterogeneity on these patterns. Journal of Insect Conservation 19:1173-1187.

Baker, H. G. 1963. Evolutionary mechanisms in pollination biology: origins and functions of floral systems are being elucidated by genetical and ecological studies. Science 139:877883.

Basu, P., A. K. Parui, S. Chatterjee, A. Dutta, P. Chakraborty, S. Roberts, and B. Smith. 2016. Scale dependent drivers of wild bee diversity in tropical heterogeneous agricultural landscapes. Ecology and Evolution 6:6983-6992.

Bluthgen, N., and A. M. Klein. 2011. Functional complementarity and specialisation: the role of biodiversity in plant-pollinator interactions. Basic and Applied Ecology 12:282-291.

Bolker, B. M., M. E. Brooks, C. J. Clark, S. W. Geange, J. R. Poulsen, M. H. H. Stevens, and J. S. White. 2009. Generalized linear mixed models: a practical guide for ecology and evolution. Trends in Ecology and Evolution 24:127-135. 
Brosi, B. J., and H. M. Briggs. 2013. Single pollinator species losses reduce floral fidelity and plant reproductive function. Proceedings of the National Academy of Sciences USA 110:13044-13048.

Buckley, L. B., and R. B. Huey. 2016. How Extreme Temperatures Impact Organisms and the Evolution of their Thermal Tolerance. Integrative and Comparative Biology 56:98-109.

Byrnes, J. E. K., L. Gamfeldt, F. Isbell, J. S. Lefcheck, J. N. Griffin, A. Hector, ... J. Emmett Duffy. 2014. Investigating the relationship between biodiversity and ecosystem multifunctionality: challenges and solutions. Methods in Ecology and Evolution 5:111-124.

Cairns, C. E., R. Villanueva-Gutiérrez, S. Koptur, and D. B. Bray. 2005. Bee populations, forest disturbance, and Africanization in Mexico. Biotropica 37:686-692.

Dicks, L. V., et al. 2016. Ten policies for pollinators. Science 354:975-976.

FAO. 2015. Food and Agriculture Organization of the United Nations Global Forest Resources Assessment, Rome, Italy.

Ferreira, P. A., D. Boscolo, L. G. Carvalheiro, J. C. Biesmeijer, P. L. B. Rocha, and B. F. Viana. 2015. Responses of bees to habitat loss in fragmented landscapes of Brazilian Atlantic Rainforest. Landscape Ecology 30:2067-2078.

Foley, J. A. 2005. Global Consequences of Land Use. Science 309:570-574.

Geslin, B., et al. 2016. Spatiotemporal changes in flying insect abundance and their functional diversity as a function of distance to natural habitats in a mass flowering crop. Agriculture, Ecosystems \& Environment 229:21-29.

Gonthier, D. J., K. K. Ennis, S. Farinas, H. Hsieh, A. L. Iverson, P. Batáry, and I. Perfecto. 2014. Biodiversity conservation in agriculture requires a multi-scale approach Biodiversity conservation in agriculture requires a multi-scale approach. Proceedings of the Royal Society B 281:20141358.

Hammer, O., D. A. T. Harper, and P. D. Ryan. 2001. PAST: Paleontological statistics software package for education and data analysis. http://palaeo-electronica.org/2001_1/past/issue 1_01.htm

Holzschuh, A., I. Steffan-Dewenter, and T. Tscharntke. 2007. Agricultural landscapes with organic crops support higher pollinator diversity. Oikos 117:354-361.

IPBES. 2016. Summary for policymakers of the assessment report of the Intergovernmental Science-Policy Platform on Biodiversity and Ecosystem Services on pollinators, pollination and food production. S.G. Potts et al. Secretariat of the Intergovernmental Science-Policy Platform on Biodiversity and Ecosystem Services, Bonn, Germany.

Jha, S., and J. H. Vandermeer. 2009. Contrasting foraging patterns for Africanized honeybees, native bees and native wasps in a tropical agroforestry landscape. Journal of Tropical Ecology $25: 13$.

Jha, S., and J. H. Vandermeer. 2010. Impacts of coffee agroforestry management on tropical bee communities. Biological Conservation 143:1423-1431.

Johnson, L. K., and S. P. Hubbell. 1974. Aggression and competition among stingless bees: field studies. Ecology 55:120127.

Jimenez-Soto, E., and S. M. Philpott. 2015. Size matters: nest colonization patterns for twig-nesting ants. Ecology and Evolution 5:3288-3298.

Kaluza, B. F., H. Wallace, T. A. Heard, A. Klein, and S. D. Leonhardt. 2016. Urban gardens promote bee foraging over natural habitats and plantations. Ecology and Evolution 6:1304-1316.

Kennedy, C. M., E. Lonsdorf, M. C. Neel, N. M. Williams, T. H. Ricketts, R. Winfree, and C. Kremen. 2013. A global quantitative synthesis of local and landscape effects on wild bee pollinators in agroecosystems. Ecology Letters 16: 584-599.

Klein, A.M., I. Steffan-Dewenter, D. Buchori and T. Tscharntke. 2002. Effects of land- use intensity in tropical agroforestry systems on coffee flower-visiting and trap-nesting bees and wasps. Conservation Biology 16:1003-1014.

Klein, A.-M., I. Steffan-Dewenter, and T. Tscharntke. $2003 a$. Bee pollination and fruit set of Coffea Arabica and C. canephora (Rubiaceae). American Journal of Botany 90:153-157.

Klein, A., I. Steffan-Dewenter, and T. Tscharntke. 2003b. Pollination of Coffea canephora in relation to local and regional agroforestry management. Journal of Applied Ecology 40:837-845.

Kovacs-Hostyanszki, A., S. Haenke, P. Batary, B. Jauker, A. Baldi, T. Tscharntke, and A. Holzschuh. 2013. Contrasting effects of mass-flowering crops on bee pollination of hedge plants at different spatial and temporal scales. Ecological Applications 23:1938-1946.

Kremen, C., N. M. Williams, M. A. Aizen, B. Gemmill-Herren, G. LeBuhn, R. Minckley, ... T. H. Ricketts. 2007. Pollination and other ecosystem services produced by mobile organisms: a conceptual framework for the effects of land-use change. Ecology Letters 10:299-314.

LeBuhn, G., et al. 2003. A standardized method for monitoring Bee Populations - The Bee Inventory (BI) Plot. Logan, UT. http://online.sfsu.edu/beeplot/

Lefcheck, J. S., J. E. K. Byrnes, F. Isbell, L. Gamfeldt, J. N. Griffin, N. Eisenhauer, ... J. E. Duffy. 2015. Biodiversity enhances ecosystem multifunctionality across trophic levels and habitats. Nature Communications 6:6936.

Leong, M., L. C. Ponisio, C. Kremen, R. W. Thorp, and G. K. Roderick. 2016a. Temporal dynamics influenced by global change: bee community phenology in urban, agricultural, and natural landscapes. Global Change Biology 22:10461053.

Mandelik, Y., R. Winfree, T. Neeson, and C. Kremen. 2012. Complementary habitat use by wild bees in agro-natural landscapes. Ecological Applications 22:1535-1546.

Michener, C. D. 1969. Comparative social behavior of bees. Annual Review of Entomology 14:1-45.

Michener, C. D., R. J. McGinley, and B. N. Danforth. 1994. The bee genera of North and Central America (Hymenoptera: Apoidea). Smithonian Institution Scholarly Press, Washington, DC

Moguel, P., and V. M. Toledo. 1999. Biodiversity conservation in traditional coffee systems of Mexico. Conservation Biology 13:11-21.

Morellato, L. P. C., et al. 2016. Linking plant phenology to conservation biology. Biological Conservation 195:60-72.

Nagamitsu, T., and T. Inoue. 1997. Aggressive foraging of social bees as a mechanism of floral resource partitioning in an Asian tropical rainforest. Oecologia 110:432-439.

Novelo, E. R., V. Melendez, and R. Ayala. 2007. Diversidad de abejas silvestres (Hymenoptera: Apoidea) en areas naturales protegidas de Yucatan, Mexico. Entomologia mexicana 6:1-7.

Olesen, J. M., J. Bascompte, H. Elberling, and P. Jordano. 2008. Temporal dynamics in a pollinator network. Ecology 86:1573-1582

Perfecto, I., R. A. Rice, R. Greenberg, and M. E. Van Der Voort. 1996. Shade coffee: a disappea refuge for biodiversity. BioScience 46:598-608.

Perfecto, I., J. Vandermeer, and S. M. Philpott. 2014. Complex ecological interactions in the coffee agroecosystem. Annual Review of Ecology, Evolution, and Systematics 45:37-58.

Peters, V. E., C. R. Carroll, R. J. Cooper, R. Greenberg, and M. Solis. 2013. The contribution of plant species with a steady-state flowering phenology to native bee conservation 
and bee pollination services. Insect Conservation and Diversity 6:45-56.

Peters, V. E., T. A. Carlo, M. A. R. Mello, R. A. Rice, D. W. Tallamy, S. A. Caudill, and T. H. Fleiming. 2016. Using plant-animal interactions to inform tree selection tree-based agroecosystems for enhanced biodiversity. BioScience 66:1046-1056.

Philpott, S. M., S. Uno, and J. Maldonado. 2006. The importance of ants and high-shade management to coffee pollination and fruit weight in Chiapas, Mexico. Biodiversity and Conservation 15:487-501.

Philpott, S. M., W. J. Arendt, I. Armbrecht, P. Bichier, T. V. Diestch, C. Gordon, ... J. M. Zolotoff. 2008. Biodiversity loss in Latin American coffee landscapes: review of the evidence on ants, birds, and trees. Conservation Biology 22:1093-1105.

Potts, S. G., V. Imperatriz-Fonseca, H. T. Ngo, M. A. Aizen, J. C. Biesmeijer, T. D. Breeze, and A. J. Vanbergen. 2016. Safeguarding pollinators and their values to human wellbeing. Nature 540:220-229.

R Core Team. 2015. R: a language and environment for statistical computing. R Foundation for Statistical Computing, Vienna, Austria. https://www.R-project.org/

Ricketts, T. H. 2004. Tropical forest fragments enhance pollinator activity in nearby coffee crops. Conservation Biology 18:1262-1271.

Rollin, O., V. Bretagnolle, L. Fortel, L. Guilbaud, and M. Henry. 2015. Habitat, spatial and temporal drivers of diversity patterns in a wild bee assemblage. Biodiversity and Conservation 24:1195-1214.

Roubik, D. W. 1978. Competitive Interactions between neotropical pollinators and Africanized honey bees. Science 201:1010-1032.

Roubik, D. W. 1989. Ecology and natural history of tropical bees. Cambridge University Press, Cambridge, United Kingdom.
Roubik, D. W., and H. Wolda. 2001. Do competing honey bees matter? Dynamics and abundance of native bees before and after honey bee invasion. Population Ecology 43:53-62.

Roubik, D. W., J. E. Moreno, C. Vergara, and D. Wittman. 1986. Sporadic food competition with African honey bee: projected impact on neotropical social bees. Journal of Tropical Ecology 2:97-111.

Samnegård, U., P. A. Hambäck, C. Eardley, S. Nemomissa, and K. Hylander. 2015. Turnover in bee species composition and functional trait distributions between seasons in a tropical agricultural landscape. Agriculture, Ecosystems and Environment 211:185-194.

Tscharntke, T., A. M. Klein, A. Kruess, I. Steffan-Dewenter, and C. Thies. 2005. Landscape perspectives on agricultural intensification and biodiversity-ecosystem service management. Ecology Letteres 8:857-874.

Tylianakis, J. M., T. A. Rand, A. Kahmen, A. M. Klein, N. Buchmann, J. Perner, and T. Tscharntke. 2008. Resource heterogeneity moderates the biodiversity-function relationship in real world ecosystems. PLoS Biology 6:0947-0956.

Veddeler, D., A. M. Klein, and T. Tscharntke. 2006. Contrasting responses of bee communities to coffee flowering at different spatial scales. Oikos 112:594-601.

Williams, N. M., E. E. Crone, T. H. Roulston, R. L. Minckley, L. Packer, and S. G. Potts. 2010. Ecological and life-history traits predict bee species responses to environmental disturbances. Biological Conservation 143:2280-2291.

Willmer, P. G., and G. N. Stone. 1989. Incidence of entomophilous pollination of lowland coffee (Coffea canephora); the role of leaf cutter bees in Papua New Guinea. Entomologia Experimentalis et Applicata 50:113-124.

Winfree, R., I. Bartomeus, and D. P. Cariveau. 2011. Native pollinators in anthropogenic habitats. Annual Review of Ecology, Evolution, and Systematics 42:1-22.

\section{SUPPORTING INFORMATION}

Additional supporting information may be found online at: http://onlinelibrary.wiley.com/doi/10.1002/eap.1568/full

Data Availability

Data available from the Dryad Digital Repository: https://doi.org/10.5061/dryad.4s51m 